\title{
DESIGN SOLUTIONS OVERVIEW OF UNIVERSAL MOTOR GEAR DRIVES WITH HELICAL GEARS
}

\author{
Milan Rackov (D), Ivan Knežević, Maja Čavić (D), Marko Penčić (D), \\ Dijana Čavić, Siniša Kuzmanović \\ University of Novi Sad, Faculty of Technical Sciences, Mechanization and Design Engineering, \\ Novi Sad, Serbia
}

\begin{abstract}
Today there are no products whose appearance is not important. Of course, the greatest attention is paid to products that are intended for mass consumption and personal use, since the customers want to emphasize their uniqueness. That doesn't mean the other products are not given any attention but on the contrary. Within this paper, only universal gear reducer with helical gears will be considered. These units are often installed within the other products, so that they are usually invisible to the customers, and this paper will give attention to their design solutions overview. Universal gear reducers are relatively simple products and around the world there is a large number of manufacturers of these gear drives of different concepts and shapes. It is interesting to note that most manufacturers try to adopt the shape of gearbox housing that is significantly different from competing solutions. The reason for that is they want to accentuate their solution in order to and to avoid the possibility of an accusation of copying some other's solution. Although, there are manufacturers which retain almost identical shape as a competing solution, which is probably a reason of bought licence or a consequence of inexperienced copying.
\end{abstract}

Key words: design solution, universal gear drives, helical gears

\section{INTRODUCTION}

Universal gear reducers, in contrast with the special gear drives, are intended for the transmission of torque and circular movement from the driving to the operating machine for different levels of power and speed as well as for different shapes and positions of installation. Because of that, they are a bit more complex to produce and have more parts than special ones (Zadnik et al, 2009). However, for smaller series, they are significantly cheaper than special reducers and can satisfy almost all customer requirements. Universal gear reducers can be divided in different ways. Today, the basic division is made according to the size of the arc of tooth clearance. There are so-called industrial gearboxes, which are most common in practice (power transmissions), and so-called gearless drives, with an arc clearance of less than 10 angular minutes, which are used only in precision engineering (motion transmitters). Further division can be made according to the position of the gears into regular gear reducers and planetary gear reducers. Within this paper, only regular (industrial) gear reducers will be considered, although today planetary gearboxes are much more used around the world, in the place where it is necessary to achieve large transmission ratios and small overall dimensions, but at a slightly higher price. Ordinary gear reducers can be divided into gearboxes with parallel and gearboxes with coaxial or almost coaxial shafts. In this paper, both types of gearboxes will be considered. Further division can be performed according to the mounting method: into gearboxes with radial, axial and both radial and axial mounting. According to the number of stages, there are single-stage, two-stage, three-stage and multistage gear reducers. According to the method of connection between the reducer and electric motor, there are gearboxes without installed motor, i.e. gearboxes supplied with a classic input shaft, gearboxes with an adapter for IEC motors, when the customer should install electric motor or when the gearbox is supplied with the electric motor. Motor gearboxes can be different: with mounted special (gearbox) electric motor or standard IEC motor. Additionally, the gearboxes can be divided according to the form of installation: footmounted, flange-mounted, foot and flange-mounted and gearboxes for mixers. Depending on the size of the gearbox, there are small (usually with an axis height less than $100 \mathrm{~mm}$ ), medium (from 100 to 500 $\mathrm{mm}$ ) and large gearboxes (over $500 \mathrm{~mm}$ ). The size of the gearbox can also have some influence on the final shape of the gearbox, i.e. its housing shape, although the efforts are made that all housings, within one row of gearboxes, are similar to each other. Only medium-sized reducers are considered in this paper (Anišić, 2004; Anišić and Krsmanović, 2008). 


\section{PROBLEM DESCRIPTION}

The shape of the gearbox largely depends on the concept of the gearbox and the adopted number of gear stages. Single-stage gearboxes are always assembled in housing for single-stage units, although there are manufacturers who do not produce single-stage gearboxes at all. Two-stage gearboxes can be assembled in special housing for two-stage or in a universal housing for two- and three-stage units. Manufacturers, who produce two-stage gearboxes in special housing for two-stage units, build their three-stage gearboxes by connecting two-stage and single-stage gearbox, or by double two-stage gearboxes, so that their three-stage (or four-stage) gearboxes are slightly more expensive than the three-stage gearboxes assembled in universal housing for two- and three-stage units. That means, if a special housing for the two-stage gearbox is used, the same housing will be used for the production of three-stage gearboxes, and if a universal housing for two-stage and three-stage gearboxes is used, it is used the same in both two-stage or three-stage version. Two-stage gearboxes are slightly more expensive than gearboxes made in a special housing for two-stage units. Depending on the market segment where the basic attention is paid, manufacturers select one of these two concepts (Kuzmanović, 2009).

\section{DESIGN SOLUTION OVERVIEW OF MOTOR GEAR UNITS}

Classic motor gearboxes (Figure 1) are, in principle, delivered with the electric motor, although this is not the rule. So, the electric motor is usually connected to the gearbox housing and forms one drive unit (Rackov, 2013).

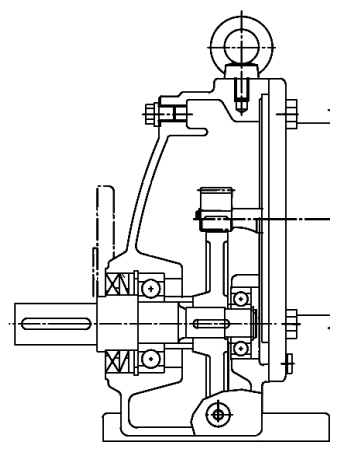

Figure 1: Characteristic solution of the single-stage gearbox, Nord (NORD Drivesystems, 2018)

These reducers are usually produced in three different installation forms: with feet, with feet and flange and with flange (Figure 2) (Rackov, 2013).

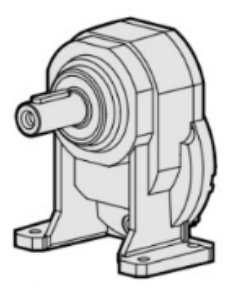

1

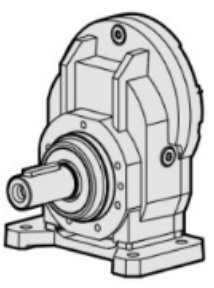

2

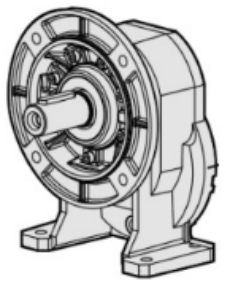

3

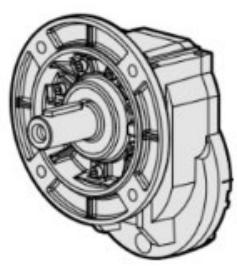

4

Figure 2: Characteristic solutions of single-stage universal gearbox: (1) foot-mounted and upper position of output shaft, (2) foot-mounted and lower position of output shaft, (3) foot and flange-mounted and (4) flange-mounted gearboxes, Motovario (Helical Geared Motors, 2018)

Some manufacturers use complex shape housings (Figure 3-1) to increase the rigidity of the gearbox unit, reduce material consumption and to improve its appearance. There are manufacturers who produce the housings in a simpler shape, with slightly higher material consumption and increase the housing surface (Figure 3-2), in order to enable to take a larger heat amount away from the unit (which occurs due to losses in the unit) to the environment. However, there are manufacturers who use a simple shape of housing, but 
achieve the high material consumption (Figure 3-3 and 3-4). Of course, simpler housing forms seem a bit outdated, but due to the possibility of taking away a larger amount of heat, they are often used in practice.

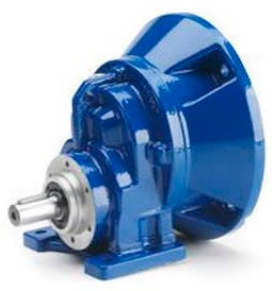

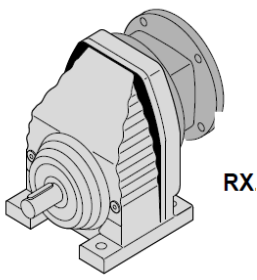

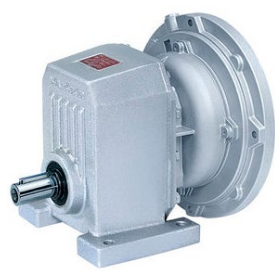

3

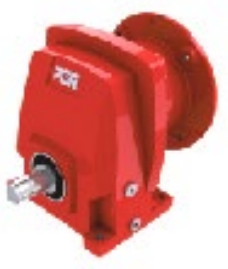

Figure 3: Characteristic solutions of single-stage universal foot-mounted gearbox: (1) solution of company STM Team (STM TEAM, 2016), (2) solution of company SEW (SEW Eurodrive, 2016), (3) solution of company Bonfiglioli (Bonfiglioli Riduttori, Anon) and (4) solution of company PGR (PGR Drive Technologies, 2011)

The manufacturers who produce motor gear reducers in special housings for two-stage gearbox (Figure 41), assemble three-stage gear units by connecting two-stage and single-stage gear reducers (Figure 4-2), and their four-stage gear reducers are assembled by connecting two units of two-stage gearbox (Figure 43). Although, there are manufacturers who produce only two-stage gear reducers. Within the gear reducers with special housing there are different kinds of interested solutions of two-stage gear reducers.

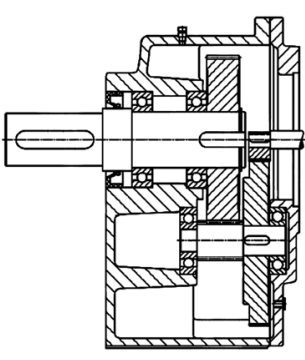

1

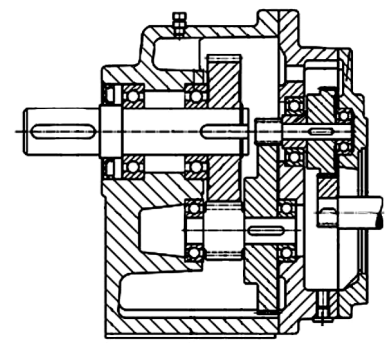

2

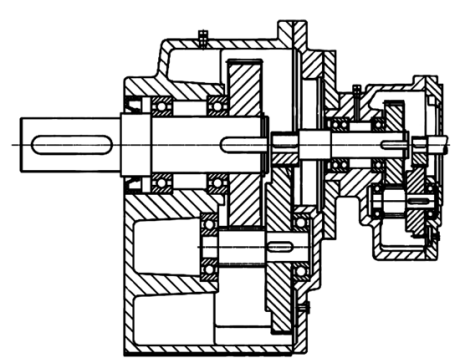

3

Figure 4: Characteristic solutions of (1) two-stage gearbox assembled in special housing for two-stage gear reducer, (2) three-stage gearbox assembled by connecting two-stage and single-stage gear reducer and (3) four-stage gearbox assembled by connecting two units of two-stage gear reducers, solution of company Bege (BEGE, 2017)

Two-stage gearboxes produced in a special housing for two-stage unit can have round housings (Figure 51 ), which fit into the circle shape of the electric motor and form an elegant shape unit. It could be also oval (Figure 5-2), square (Figure 5-3) and completely square unit (Figure 5-4). Square housings seem a bit awkward and require the highest material consumption, so they are less common in practice. They have the largest surface area and are suitable for fast dissipation of heat (which occurs due to losses in the gearbox) to the surrounding air.

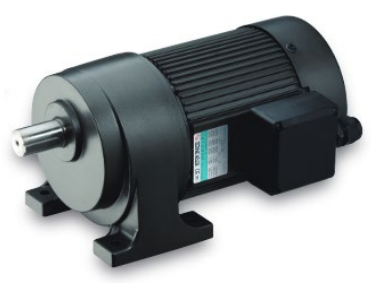

1

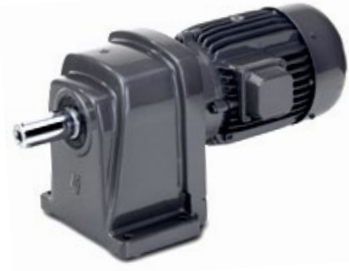

2

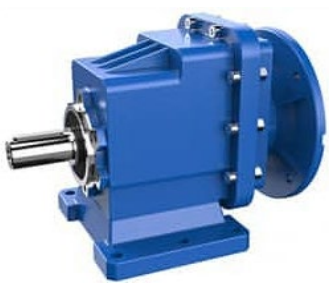

3

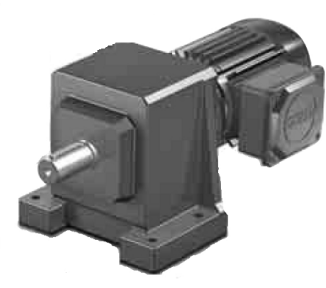

4

Figure 5: Characteristic solutions of two-stage universal foot-mounted gearbox: (1) solution of company Sesame (Sesame, 2020), (2) solution of company Bege (BEGE, 2017), (3) solution of company Aokman (AOKMAN drive, 2020) and (4) solution of company Stöber (SMS/MGS Gearunits, Anon) 
Three-stage and four-stage gear reducers that are built by connecting two-stage and single-stage (Figure 6-1) or two units of two-stages (Figure 6-2) gear units seem quite large, but these solutions are offered only in the cases when large gear ratios are required, which is still a rare situation.

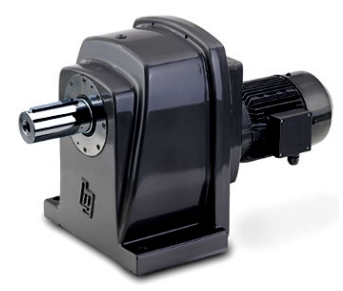

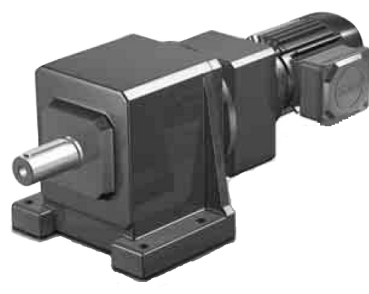

2

Figure 6: Characteristic solutions of three-stage and four-stage universal motor gear reducers built by connecting two-stage and single-stage (1) Bege (BEGE, 2017) or by two units of two-stages gearboxes (2) Stöber (SMS/MGS Gearunits, Anon)

Two-stage and three-stage motor gear reducers assembled in universal housing for two-stage and threestage unit do not have major difference in design of these two types of gearboxes (Figure 7).

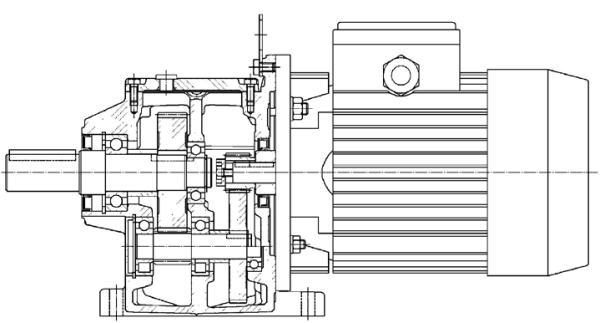

1

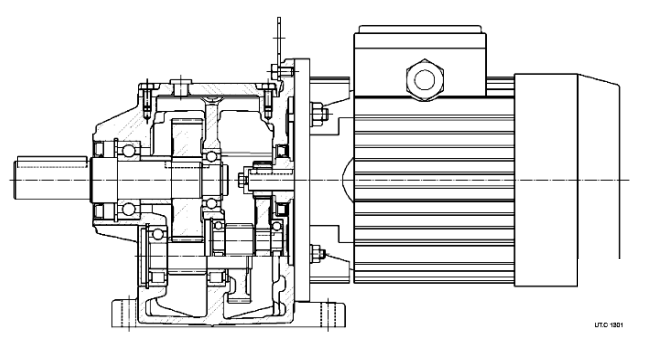

2

Figure 7: Characteristic solutions of two-stage motor gear reducer universal housing for two-stage and three-stage units (1) and three-stage motor gear reducer built in the same housing (2), solution of company Rossi (Rossi, Anon)

Gear reducers built in the universal housings for two-stage and three-stage units are distinguished in the mounting method. An axial mounting can be used, but it is now an old solution (Figure 8) and there is both radial and axial mounting. In this combined way of mounting, there is a difference between the shapes of the gearbox housings. The housing can have open slow-motion chamber (Figure 9) or it can have open both chambers (Figure 10), through which the large gears are installed.

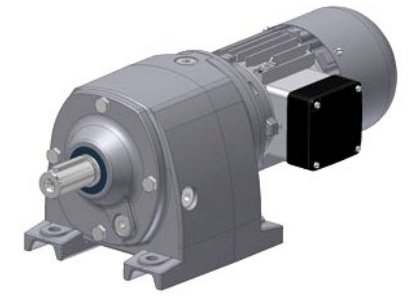

1

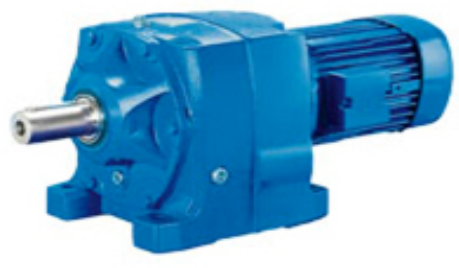

2

Figure 8: Characteristic solutions of two-stage and three-stage motor gear reducers with axial mounting, (1) solution of company Himel (Himmel, 2020) and (2) solution of company Premium Stephan (Premium Stephan, 2020) 


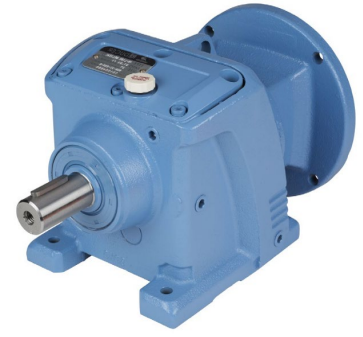

1

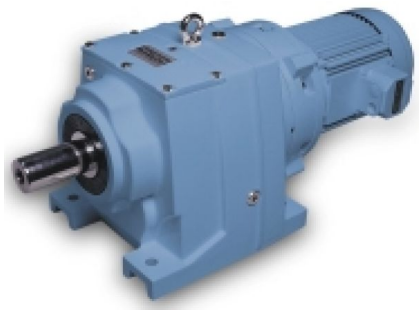

2

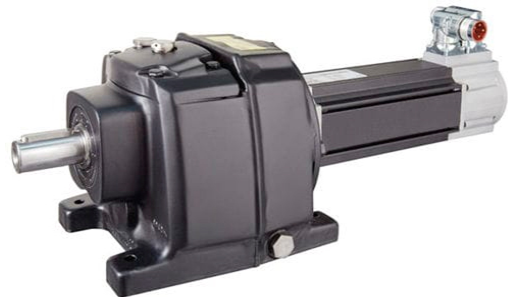

3

Figure 9: Characteristic solutions of two-stage and three-stage motor gear reducers with both radial and axial mounting and open slow-motion chamber, (1) solution of company Iron Horse (Automation Direct, 2020), (2) ASC (ASC, 2020) and (3) Leroy Somer (Leroy Somer, 2020)

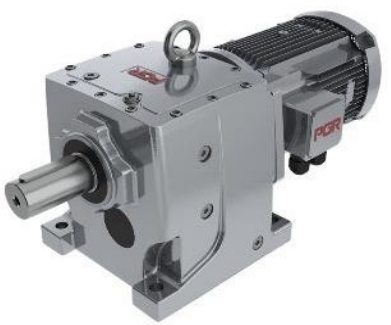

1

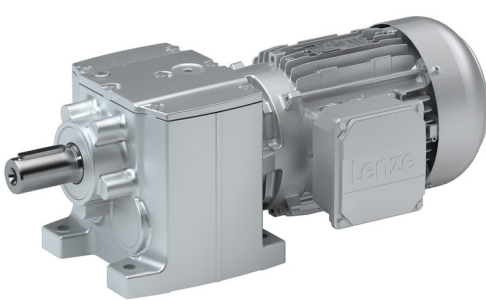

2

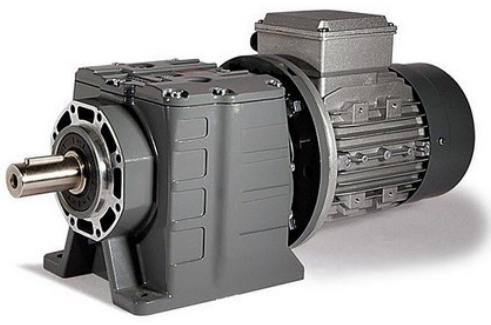

3

Figure 10: Characteristic solutions of two-stage and three-stage motor gear reducers with both radial and axial mounting and open both chamber, (1) solution of company PGR (PGR Drive Technologies, 2011), (2) Lenze (Lenze, 2020) and (3) Varvel (Varvel, 2020)

There are also gearboxes that are built in universal gearbox housing with feet and a flange. These housings are designed for flanged gearboxes, but the feet can be connected if necessary (Figure 11).

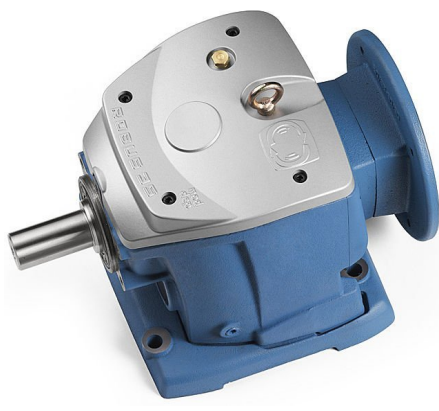

1

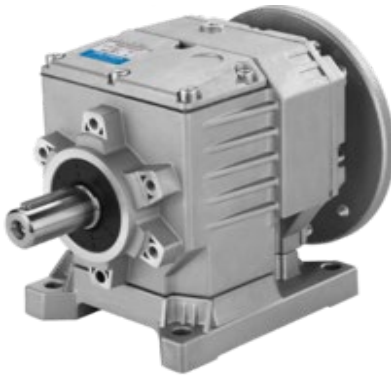

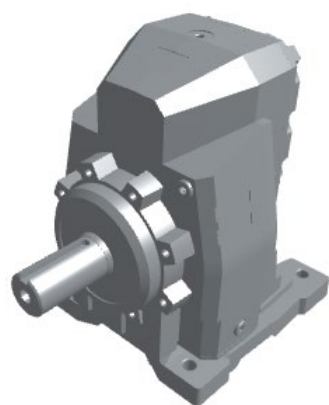

3

Figure 11: Characteristic solutions of two-stage and three-stage motor gear reducers with universal housing,

(1) solution of company Robus (Motive, 2020), (2) MSF (MSF, 2020) and (3) Regal (REGAL, 2020)

There are universal gearbox housings that can be used for foot connection, flange connection and foot and flange connection at the same time (Figure 12). 


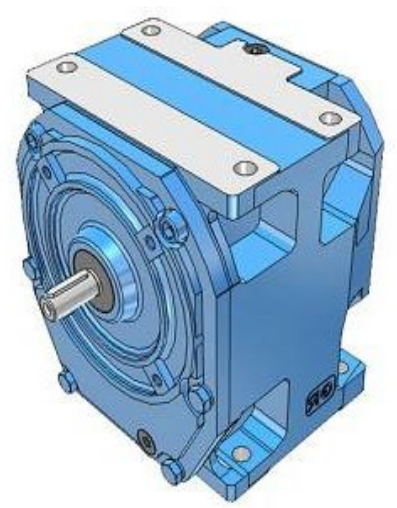

Figure 12: Characteristic solutions of two-stage and three-stage gear reducers with universal housing, solution of company Rossi (Rossi, Anon)

\subsection{Classic Gear Drives}

Classic gear drives are gear reducers with parallel shafts, which are not intended for direct installation to the electric motor, although some solutions can be delivered in this way. The number of gear stages does not significantly affect their shape (Figure 13). The main fault of these gear units is that the electric motor must be grounded separately and the shaft of the electric motor must be centred with the input shaft of the gearbox. Therefore, the concept of these gear units is often found only in large gearboxes.

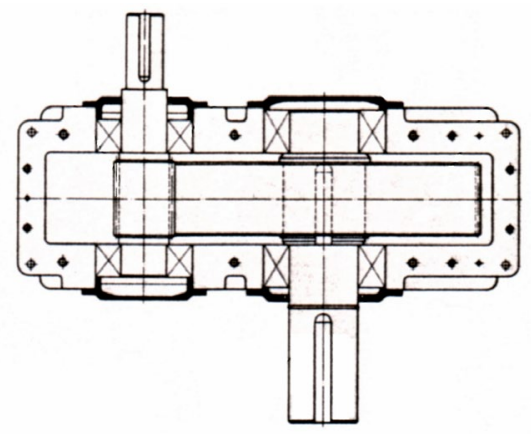

Figure 13: Characteristic solutions of single-stage gear reducer with parallel shafts, solution of company Santasalo (DB Santasalo, 2020)

The shape of the housing of single-stage gearboxes mostly depends on the position of the shaft and the way of the installation. Regarding the position of the shaft, there are gearboxes with horizontal (Figure 14) and vertical position of the shaft. Gearboxes with horizontal shaft position are usually made with radial installation. They are used for a long time and have an extremely intensive development of shapes, so that from the once common, now old-fashion shape, they have experienced a very interesting modern shape. For older solutions, the functionality and material consumption were important, while today the main attention is paid to aesthetics (Figure 14-4,5). Modern solutions are noticeable with a simple and likeable shape, with slight line transitions and slightly higher material consumption.

The housings of older solutions of these gear units consist of two parts. (Figs. 14-1 and 2), which required more extensive machining. It was necessary to machine large support surfaces, then connecting and centering both parts and further machining of cylindrical supports for bearings. Modern solutions use one-piece housings, much simpler to a machine, but somewhat more complex to assemble. In larger series, the housings are usually made by casting, while in smaller series and larger dimensions, the housings are usually made by welding.

In the case the reducer operates in an environment with higher ambient temperature, as well as connected with higher engine powers, where higher losses in the reducer can be expected, the housings must be made with ribs (Figs. 14-2 and 3) in order to increase the external housing surface and thus improved heat dissipation. In the case of gearboxes of larger dimensions, ribs are also made, but in order to increase the rigidity of the housing. 


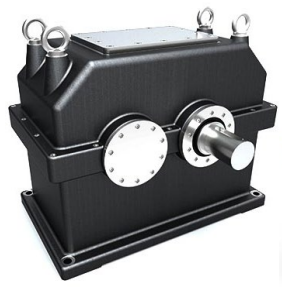

1

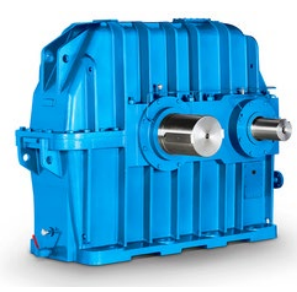

2

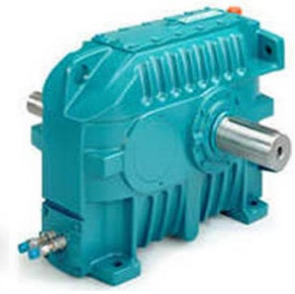

3

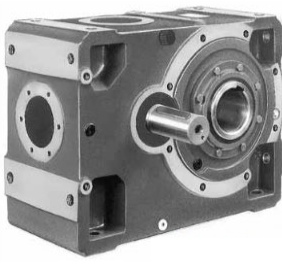

4

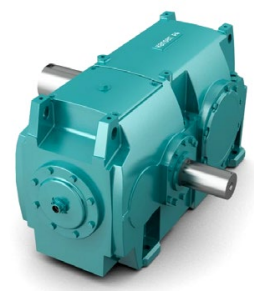

5

Figure 14: Characteristic solutions of single-stage gear reducers with parallel shafts and foot-mounted, (1) solution of company Kissling (Kissling, Anon), (2) Flender (Flender, Anon), (3) Hansen, (4) Rossi (Rossi, Anon) and (5) Hansen (Hansen, Anon)

In order to simplify the production of the gear units, many manufacturers of smaller gearboxes make one-piece housings, in order to avoid machining of large contact surfaces of two parts. They also install a large access hole, through which, during installation, the large gears are installed (Figure 14-3). Otherwise, the housing can have a large opening at the front surfaces, which is closed with a lid (Figs. 144 and 5), so the large gears are installed through them. This approach significantly simplifies the machining of the housings, although the assembling of such reducers is somewhat more complex.

Today, the basic attention of designers is paid to the aesthetics of the gearbox, i.e. its product design. Modern solutions of single-stage universal gear reducers have a simple and likeable shape, with slight surface transitions and slightly higher material consumption. It is interesting to note that some manufacturers produce single-stage gearboxes in housing for two-stage gearboxes (intended for bevel and helical gear reducers), which makes great savings.

In order to further increase the universal using of their gearboxes, some manufacturers place the feet on all four side surfaces. In this case, the gearboxes can have both horizontal and vertical shaft arrangement (Figure 14-4). Additionally, these gearboxes, as already mentioned, have an opening on one of the side or front sides of the housing, through which the gear is inserted. It is practiced to make a flange on the front surfaces of these reducers and thus further increase the universality of these gear drives (Figure 14-4).

\subsection{Shaft-Mounted Gear Drives}

Besides universal helical gear reducers, there are so-called shaft-mounted gear reducers or flat gear reducers. Shaft-mounted gear units are only the gearboxes made with a hollow shaft. The main advantage of these gearboxes is to avoid the using of a coupling, which connects the gearbox with the operating machine, and to avoid the need to center the axis of the output shaft of the gearbox with the input shaft of the operating machine. These advantages have conditioned the large application of these reducers, despite the fact that it is necessary to solve the fixing of these units, so to support the reaction torque, i.e. to prevent the unit from rotating around the output shaft. Shaft-mounted gear reducers can be divided according to the mounting method, so there are gearboxes with axial and with radial and axial mounting, i.e. with a two-part and one-part housing. The characteristic solution of a single-stage reducer with axial mounting is shown in Figure 15.

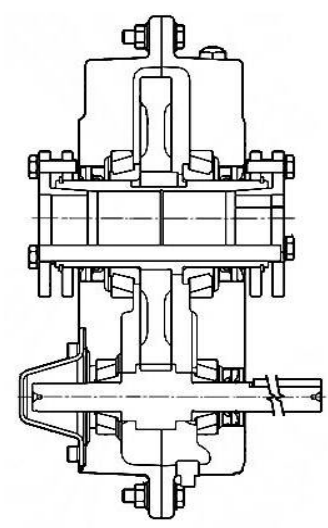

Figure 15: Characteristic solutions of single-stage shaft-mounted gear reducers with two-part housing, solution of company Dodge (Rehfuss, 2020) 
The basic feature of the two-part housings is the need for machining large contact surfaces, placing pins for centering the axis and further processing of the housing, while the transmission assembly is very simple for axial mounting, which can be done almost entirely outside the gearbox housing. Single-stage shaft-mounted gearboxes are generally simple and likeable round shape of the housing (Figure 16).

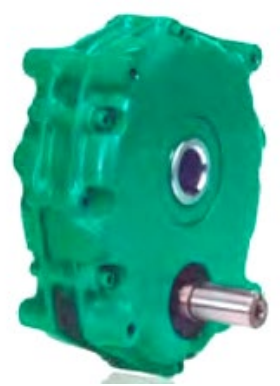

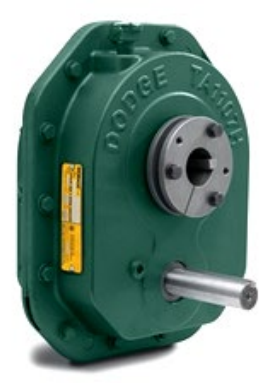

2

Figure 16: Characteristic solutions of single-stage shaft-mounted gear reducers,

(1) solution of company Leroy Somer (Poulibloc, 2000) and (2) solution of company Dodge (Rehfuss, 2020)

Two-stage and three-stage shaft-mounted gearboxes are not different significantly in the shape from single-stage gear units (Figure 17).

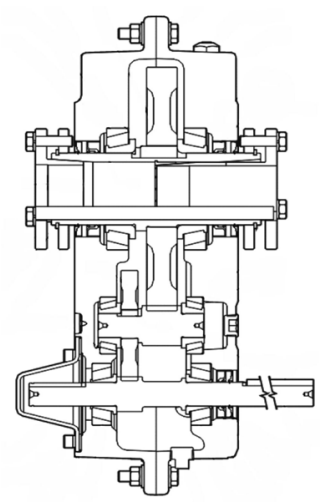

Figure 17: Characteristic solutions of two-stage shaft-mounted gearbox, solution of company Dodge (Rehfuss, 2020)

Due to the savings of material, round housings (Figure 18-1) are also present in two-stage gearboxes. Although, oval (Figure 18-2) and square (Figure 18-3) housings can be also found, mainly due to easier handling during their machining. They seem more likeable and are more common in practice.

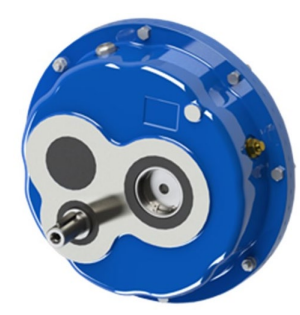

1

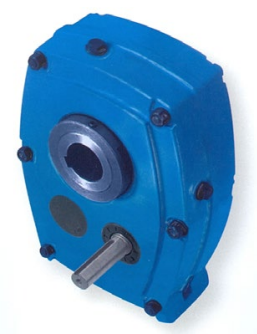

2

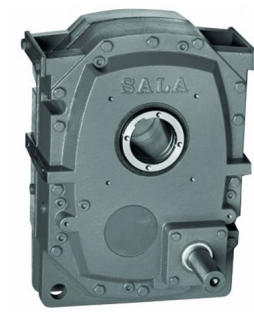

3

Figure 18: Characteristic solutions of two-stage shaft-mounted gearbox,

(1) solution of company Bonfiglioli (Bonfiglioli Riduttori, Anon), (2) Renold (Renold, 2020) and (3) Sala (ASC, 2020)

In order to avoid the processing of large adjacent surfaces, i.e. two-part housings, today most of the manufacturers of shaft-mounted (flat) gearboxes make these units as a one-part housing (Figure 19). This solution makes easier their manufacture, but complicates their assembling. Flat shaft-mounting 
gearboxes are often made as foot-mounted with the classic output shaft, in order to enable the greater application of these gearboxes, so to make some space savings in the axial direction.

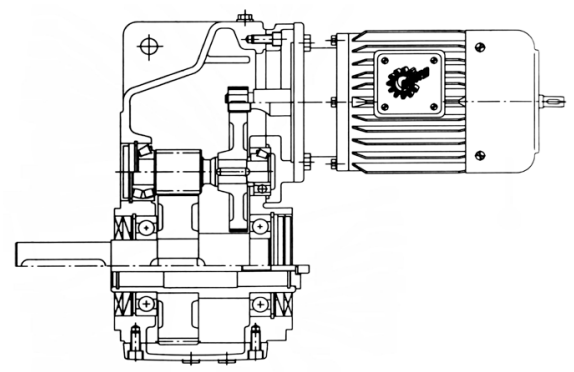

Figure 19: Characteristic solutions of two-stage shaft-mounted gearbox, solution of company Nord (NORD Drivesystems, 2018)

Flat shaft-mounted gearboxes with one-part housing are made in different versions. Some manufacturers make them as highly universal units (Figure 20-1), suitable for different shapes and mounting positions. There are also manufacturers who make them only as a shaft-mounted version (Figure 20-2 and 3).

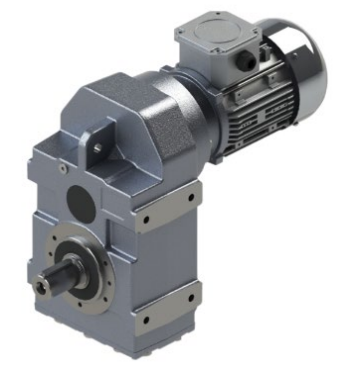

1

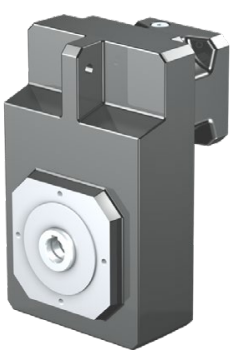

2

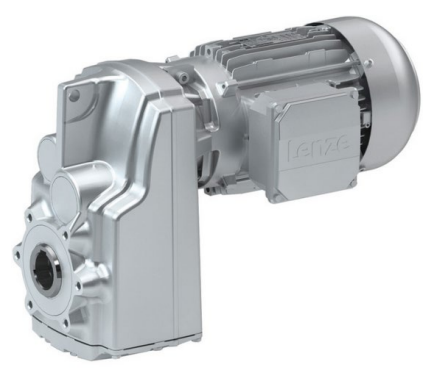

3

Figure 20: Characteristic solutions of shaft-mounted gearbox with axial assembling, (1) solution of company PGR (PGR Drive Technologies, 2011), (2) Stöber (SMS/MGS Gearunits, Anon) and (3) Lenze (Lenze, 2020)

Of course, there are also three-stage versions with a highly universal housing (Figure 21), intended for different shapes and positions of installation (Figure 22), which significantly expands the scope of their application.

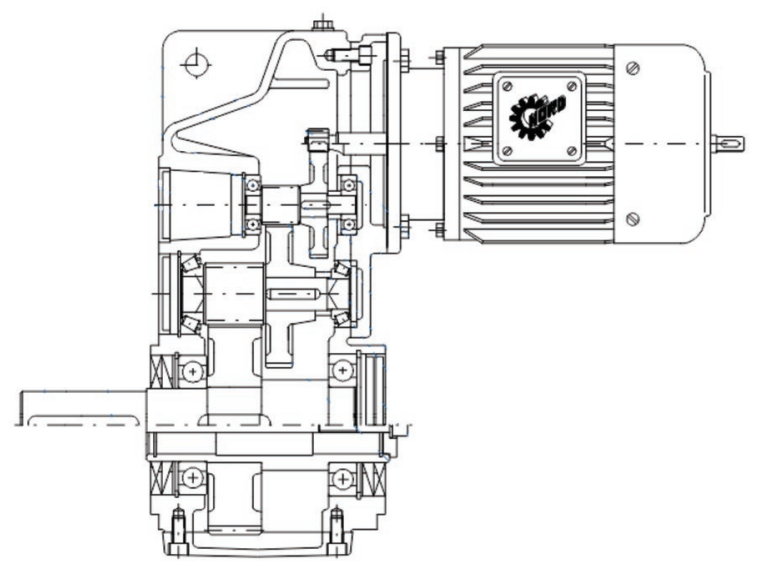

Figure 21: Characteristic solutions of three-stage flat shaft-mounted gearbox, solution of company Nord (NORD Drivesystems, 2018) 


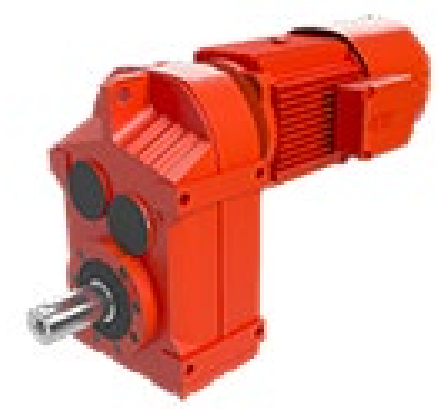

Figure 22: Characteristic solutions of three-stage flat shaft-mounted gearbox, solution of company SEW (SEW Eurodrive, 2016)

\section{ANALYSIS OF GIVEN SOLUTIONS}

Regarding the extent of the assortment, i.e. the number of types, size, the shape and mounting position, it is different for each manufacturer. It certainly depends on the capabilities of the manufacturer and the current market demands. However, it is evident that the shape of the housing, and thus the whole gearbox, is given extremely great designers attention. Each manufacturer wants to define a specific shape of the gearbox, which will distinguish it from the competition, and to use a specific (own) factory color that will immediately identify the manufacturer of the gearbox. Of course, at the customer's request, the gearboxes can be painted in a different color, but the manufacturers charge this extra. It is the reason why the gearboxes are usually delivered in the factory color, and the customers, if they want, later paint according to their taste.

\section{EXPECTED DIRECTIONS OF FURTHER DEVELOPMENT}

Based on the realized and presented solutions of the world's leading manufacturers of gear reducers, it follows that intensive development of all types of gearboxes can still be expected.

Motor gearboxes (with vertical shaft assembling) foot-mounted, flange-mounted and feet and flangemounted are the basic forms of the housings that will be the most required in the future due to relatively low production costs, harmonious shape and low material consumption. Universal shapes are less demanded and can be only produced by smaller gear reducer manufacturers that are based on the segment of the market requirements that is not covered by large manufacturers.

Classic gearboxes (with horizontal shaft assembling) foot-mounted on all side surfaces and with flanges on the front surfaces are the most universal gear units. They are adapted for all shapes and mounting positions, but they are also the most expensive gearboxes, due to extensive machining and highest material consumption. Therefore, their development and application can be less intensive than the first ones. The great weakness of these reducers is, most often, the separate connection between the electric motor and the housing, i.e. the need for a special foundation and centering of the electric motor, which is not the case with motor gear reducers. They will be produced by only a small number of manufacturers in order to meet the special requirements of the industrial machines.

In the case of shaft-mounted gearboxes, intensive development of these reducers can still be expected, since they make installation easier, i.e. there is no need to use (expensive) coupling on the output shaft of the gearbox and there is no need for centering. Additionally, they provide a more compact and simpler construction because it does not require a classic foundation of gearboxes, which is a great advantage. Therefore, their development and application can be expected to be further intensified and more applied in industry.

\section{CONCLUSIONS}

Besides functional requirements, it is evident that modern housing solutions put first aesthetic requirements, regardless of material consumption and complexity of the product. The gearbox design increasingly plays a major role in the selection of gearboxes and despite the fact that gearboxes are installed only in the industrial machines and usually are not in the direct view area of the observer. Since 
today the gearboxes are fairly uniform in terms of quality, technical characteristics and price, special attention is paid to the design of the gearbox because an attractive gearbox always draws the attention of the observer (customer) and based on it makes the final decision about the purchase. This conclusion can be reached by observing and analyzing the implemented solutions of all the world's leading gear manufacturers.

\section{ACKNOWLEDGMENTS}

This paper has been supported by the Ministry of Education, Science and Technological Development through the project no. 451-03-68/2020-14/200156: "Innovative scientific and artistic research from the FTS (activity) domain".

\section{REFERENCES}

[1] Anišić, Z., Krsmanović, C.: “Assembly Initiated Production as a Prerequisite for Mass Customization and Effective Manufacturing", Strojniški vestnik - Journal of Mechanical Engineering 54 (9), 607-618, 2008.

[2] Anišić, Z., Ćosić, I., Kuzmanović, S.: "The Influence of Customization and Requests for Prompt Delivery on Gearmotor Design Concept", Proceedings of Tools'2004 Conference 2004, (Kočovce, Slovakia, 2004), pages 68-74.

[3] AOKMAN drive, Standard Gearbox, AOKMAN, URL: https://www.aokman-gearbox.com/standardgearbox/ (last request: 2020-09-18).

[4] ASC, Antriebe Distribution and Service GMBH, ASC, URL: https://www.ascantriebe.at/en/products/shaft_mount_gearboxes/sala_shaftmount_ gearbox_series_j/ (last request: 2020-09-18).

[5] ASC, Antribe distribution and service GMBH, ASC, URL: https://www.asc-antriebe.at/en/products/ geared_motors/helical_geared_motor_series_m/ (last request: 2020-09-18).

[6] BEGE, Motorreductoren Stirnrad-Getriebemotoren, Helical Gear Motors Motoréducteurs.

[7] Bonfiglioli Riduttori, S series, Single Stage Gearboxes, COD. 1044 R8, 120127, Bologna, Italy.

[8] General Purpose Cast Iron Helical Inline Gearboxes, Automation Direct, URL: https://www.automationdirect.com/adc/overview/catalog/power_transmission_(mechanical)/ general_purpose_cast_iron_helical_inline_gearboxes (last request: 2020-09-18).

[9] DB Santasalo, David Brown Santasalo, Products, AMF Series - Agitator, Mixer and Flotation Drives, URL: https://dbsantasalo.com/products/amf-series/ (last request: 2020-09-18).

[10] Flender, gear units, Catalog MD 20.1-2009, Siemens AG.

[11] Hansen, P4 standardized heavy duty single stage gear units catalogue, DOC-CAM626E/0613.

[12] Helical Geared Motors, Motovario S.p.A., H/2018/Rev.0.

[13] Himmel geardrive, Parallel shaft helical geared motors and parallel shaft helical gear units, URL: http://www.himmel-gear.com/htm/industry/is_06_17.php?block=sub4 (last request: 2020-09-18).

[14] Kissling, The Gear Company, Catalog Helical and bevel-helical gear reducers.

[15] Kuzmanović, S.: "Universal Helical Gear Reducers", (Faculty of Technical Sciences: Novi Sad, 2009).

[16] Lenze, Stirnradgetriebe GST, Robuster Aufbau mit hohem Wirkungsgrad, Lenze, URL: https://www.lenze.com/de-de/produkte/vorgaengerprodukte/getriebe/stirnradgetriebe-gst/ (last request: 2020-09-18).

[17] Leroy Somer catalogue, Shaft mount speed reducer, 3780 en - 2017.06/e.

[18] Motive, The gearbox model ROBUS-A completes ROBUS range, ROBUS-A gearboxes, Motive, URL: https://motive.it/en/p-13-robus-a-gearboxes.html (last request: 2020-09-18).

[19] MSF Vathauver ANTRIEBSTECHNICK, Gears, MSF-Technik, URL: http://www.msftechnik.de/en/products/motors-gears/gears/helical-gear-ms-hy/ (last request: 2020-09-18).

[20] NORD Drivesystems, Standard Helical Gearboxes, Getriebebau Nord, Hamburg, 2018.

[21] PGR Drive Technologies, Catalogue Helical Gear Units, PA/PF series 02/2017. Hélicoïdaux, BEGE, URL: https://www.bege.nl/downloads/catalogues/BEGE\%20G-DSG\%20201710\%20NL\%20DE\%20GB\%20FR.pdf (last request: 2020-09-18).

[22] Poulibloc 2000, Reducer with exclusive taper bushing feature, Catalogue Leroy Somer.

[23] Premium Stephan, Geared motors, Premium Stephan, URL: https://www.premiumstephan.com/en/products/geared-motors/ (last request: 2020-09-18). 
[24] Rackov, M.: "Conceptions of Development of Universal Gear Reducers", PhD thesis, The University of Novi Sad, Faculty of Technical Sciences, 2013.

[25] REGAL, Parallel Shaft Gearing, Regal, URL: https://www.regalbeloit.com/products/gearing/parallelshaft-gearing (last request: 2020-09-18) (last request: 2020-09-18).

[26] Rehfuss, URL: https://www.rehfuss.com/de/ (last request: 2020-09-18).

[27] Renold, Gears \& Gearboxes, Renold, URL: https://www.renold.com/products/gears-gearboxes/ (last request: 2020-09-18).

[28] Rossi, Parallel shaft gear reducers catalogue, 004BRO.GPR-de1105HQR.

[29] Sesame, Foot-mount type, Sesame, URL: https://www.sesamemotor.com/en/products/detail/18 (last request: 2020-09-18).

[30] SEW Eurodrive, Catalogue - Gear Units, Edition 06/2016-16997611.

[31] SMS/MGS Gearunits, Catalogue 11, STÖBER Antriebstechnik GmbH \& Co. KG.

[32] STM TEAM catalogue, CT17 IGBD 3.1 | ITA - ENG - DEU, 3/2016.

[33] Varvel, RD Series, Varvel, URL: https://varvel.com/en/products/rd-series/ (last request: 2020-09-18).

[34] Zadnik, Ž., Karakašić, M., Kljajin, M., Duhovnik, J.: "Function and functionality in the conceptual design process", Strojniški vestnik - Journal of Mechanical Engineering 55 (7-8), 0039-2480, 2009.

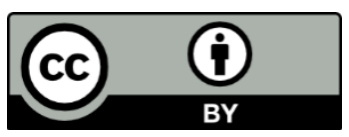

(C) 2020 Authors. Published by the University of Novi Sad, Faculty of Technical Sciences, Department of Graphic Engineering and Design. This article is an open access article distributed under the terms and conditions of the Creative Commons Attribution license 3.0 Serbia (http://creativecommons.org/licenses/by/3.0/rs/). 